\title{
Laparoscopic Excision of Calcified Collagenous Nodule of Anterior Abdominal Wall
}

\section{Authors \\ Girish D Bakhshi, Mukund B Tayade,Kavita V Jadhav, Dayanand D Choure, Pravin N Shingade, Dinesh S Pawar}

Department of General Surgery, Grant Govt Medical College \& Sir J.J.Group of Hospitals, Mumabi-08

Abstract
Collagenous nodule of anterior abdominal wall is a rare entity. Hyaline degeneration of the connective tis-
sue is the predominant pathologic feature of a collagenous nodule. Very few reports of this have been re-
ported uptil now. Collagenous nodules of pleura, of skin in patients of scleroderma are known. Collagenous
nodules of retroperitoneum, uterus and liver have been reported which are rare. Mostly laparotomy with
excision and histopathology give the diagnosis in such cases. However, in present era of minimal access
surgery, laparoscopic approach serves both diagnostic and therapeutic advantage in such rare entity. We
present a case of laparoscopic excision of collagenous nodule of anterior abdominal wall.
Key Words: Calicified Collagenous nodule

\section{INTRODUCTION}

The predominant pathologic feature of a collagenous nodule is hyaline degeneration of connective tissue. This kind of degenerative alteration can be found in atrophic breast tissue, scar tissue, atheromatous plaques, and organized tissue ${ }^{1}$. Keloid is one of the variant of it. However sometimes collagenous nodules get completely calcified and may mimick a foreign body or a stone depending upon its location. Collagenous nodule of peritoneum or anterior abdominal wall without any history of aetiology is rare.

\section{CASE REPORT}

48 years old male presented with chronic dull aching pain in right iliac fossa for 6 months. Patient had no other complaints. Patient had no history of trauma, prior surgery, fever or history of tuberculosis.
All routine blood investigations were within normal limits. Chest xray was normal. Abdominal xray in standing position was suggestive of radioopaque lesion in right iliac fossa (RIF) region. Ultrasonography (USG) and computed tomography (CT) of abdomen and pelvis was suggestive of $5 \times 4.7 \times 4.2$ sized well defined, multilobulated densely calcified lesion in RIF region. It was abutting distal ileal loops but perilesional fat planes were well maintained (Fig.1a \& 1b).

Diagnostic laparoscopy was done. Intraoperatively pearly white multilobulated mass was found in RIF region (Fig.2a \& 2b). It was attached to peritoneum protruding over bowel but not adherent to bowel. Laparoscopic excision was performed. Specimen was sent for histopathogy examination (HPE) (Fig.3). HPE report was suggestive of calcified collagenous nodule. 


\section{JMSCR Vol||04||Issue||04||Page 10234-10236||April}

Postopeartive course of patient was uneventful and patient was discharged on day 2 of surgery.Patient followed up over 2 years was found to be symptom free.
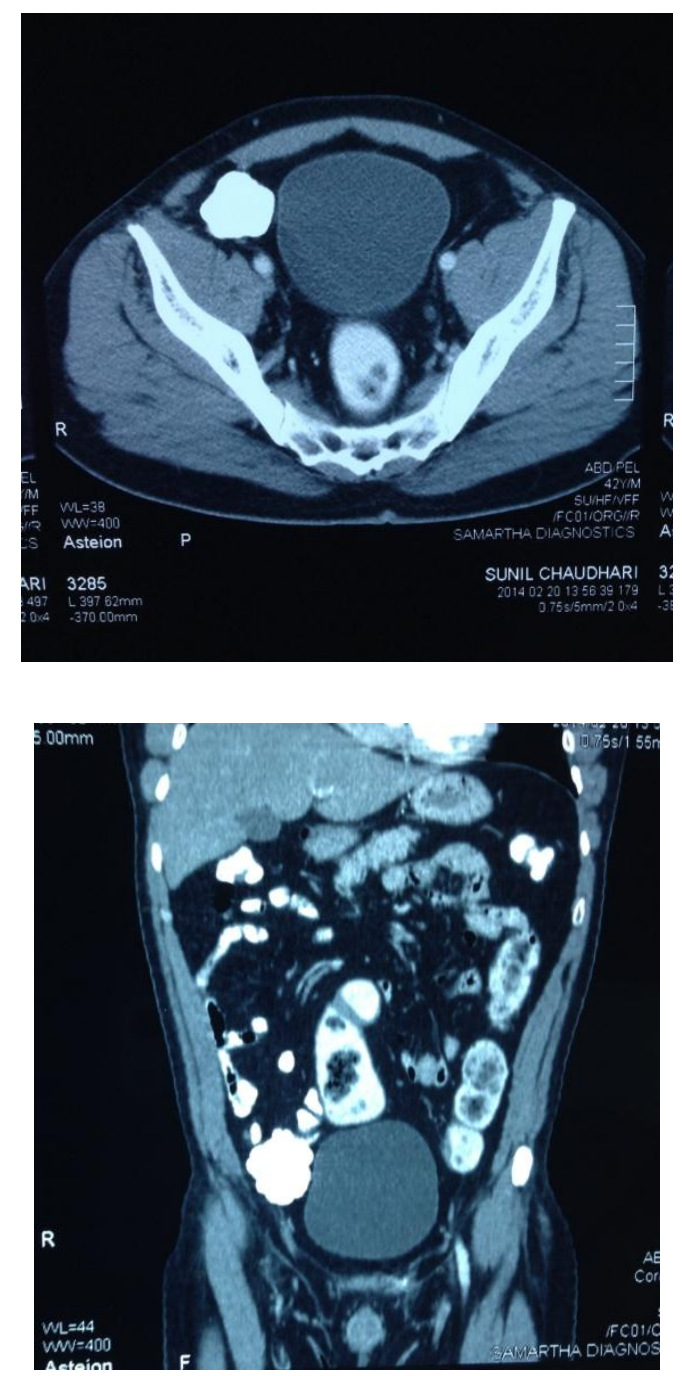

Fig.1a \& 1b - CT axial \& coronal views showing calcified collagenous nodule in RIF.

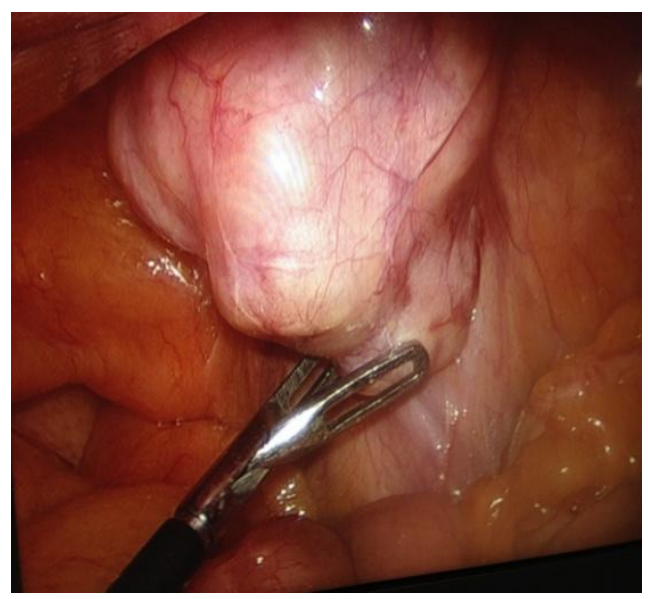

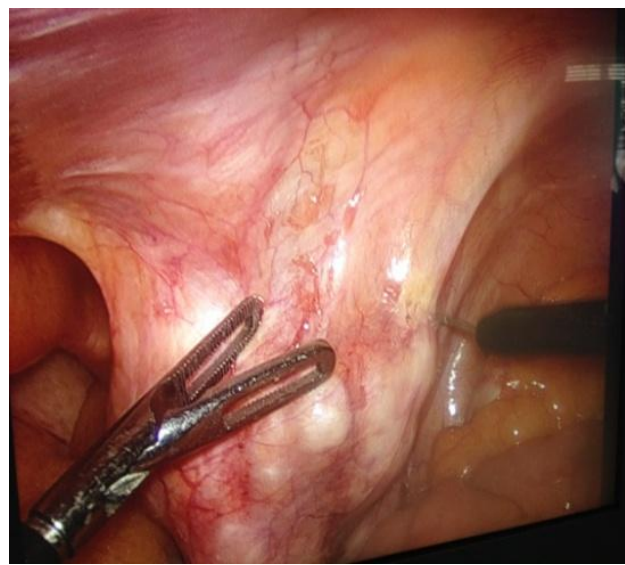

Fig.2a \& 2b - Intraoperative images showing collagenous nodule

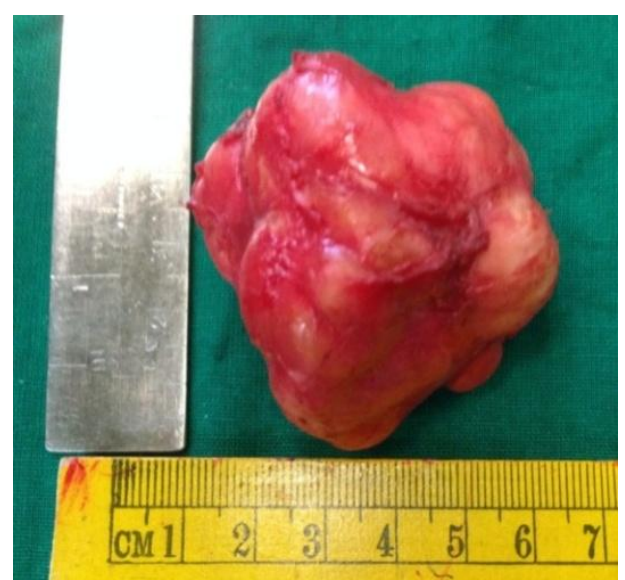

Fig. 3 - Specimen of collagenous nodule

\section{DISCUSSION}

Primary tumours of peritoneum are rare. Solitary tumour with complete calicification is rarer. Solitary fibrous tumour of pleura is more common. Mesotheliomas are common tumours of pleura \& peritoneum. Mesotheliomas can be benign or malignant.

Malignant mesothelioma is an important differential for solid peritoneal mass. Localized peritoneal malignant mesothelioma appears as a heterogeneous, solid intraperitoneal mass on cross-sectional images. The margins are often irregular. Invasion of adjacent visceral structures such as the liver, spleen, or pelvic organs may occur. Localized, loculated ascitic fluid may be present, but manifestations of diffuse peritoneal involvement, such as generalized ascites, omental caking, and peritoneal nodularity, do not typically occur ${ }^{2}$. Calcifications have been reported in localized malignant mesothelioma of the pleura. 
Raymond and Wang et $\mathrm{al}^{3}$ reported Benign collagenous nodule of the pleura associated with pleural plaques in a patient with a history of potential asbestos exposure. Zheng and Zhang et al ${ }^{1}$ reported a case of Collagenous nodule mixed simple cyst and hemangioma coexistence in the liver which was managed by them with excision.

Very less literature is available on calcified collagenous nodule per say, but in literature, few cases have been reported on solitary fibrous tumour. Lau \& Foo et $\mathrm{al}^{4}$ reported a solitory fibrous tumour of small bowel mesentery which they excised with open surgery. Peksa et $\mathrm{al}^{5}$ reported solitary fibrous tumour of retroperitonium in pregnancy which was removed with laparotomy.

Garteiz-Martinez \& Romero-Laet $\mathrm{al}^{6}$ reported a laparoscopic excision of incidental pelvic peritoneal 22 gm solitary fibrous nodule while operating for ectopic pregnancy. Patriti \& Rondelli et $\mathrm{al}^{7}$ reported laparoscopic treatment of a solitary fibrous tumour of great omentum presenting as spontaneous hemoperitonium.

SFTs and collagenous nodule more commonly affect pleura. Most of the cases of peritoneum or abdomen presented found to be more common in reproductive age group females and SFT was found incidently. Very few of them have been managed by laparoscopically as per literature review.

In present case, patient was 48 years old male with chronic pain. Diagnostic laparoscopy found pearly white multilobulated mass from peritoneum protruding over bowel. Excision was done laparoscopically. Histopatholgy examination of it was suggestive of calicified collagenous nodule. Idiopathic primary solitary calicified collagenous nodule of peritoneum is very rare. Laparoscopy helped in establishment of diagnosis and therapeutic intervention. This is probable one of the rarest case of laparoscopic excision of calcified collagenous nodule of peritoneum.

\section{REFERANCES}

1. Zheng Z, Zhang S, Cao Y, Pu G, Liu H et al. Collagenous nodule mixed simple cyst and hemangioma coexistence in the liver. World J Gastroenterol. 2015; 21: 4419-22.

2. CrottyT, Myers J, Katzenstein A, Tazelaar H, Swensen S, Churg A. Localized malignant mesothelioma: a clinicopathologic and flow cytometric study. Am J Surg Pathol 1994; 18: 357-63.

3. Raymond J, Wang $\mathrm{N}$ et al. Benign collagenous nodule of the pleura associated with pleural plaques. J Can Assoc Radiol. 1985 ; $36: 71-3$.

4. Lau M, Foo J, Sissons C, Kiruparan P et al. Solitary fibrous tumour of small bowel mesentery : a case report and review of literature. Tumori J 2010; 96 : 1035-9.

5. Peksa M, Bockowski m, Preis K et al. Solitary fibrous tumour of retroperitoneum in pregnancy : a case report. Ginekol Pol J. 2011; 82 : 382-5.

6. Garteiz MD, Romero LP, Maya GD, Weber SA, Bravo TC et al. Pelvic solitary fibrous nodule, incidental finding and laparoscopic resection. A case report. Gynaecol obstet Mex 2010; 78 ; 504-8

7. Patriti A, Rondelli F, Gulla n, Donini A et al. Laparoscopic treatment of a solitary fibrous tumour of the greater omentum presenting as spontaneous haemoperitoneum. Ann Ital chir j. 2006; $77: 351-3$. 